\title{
ARAC's Operational Support of the Cassini Launch
}

\author{
J.C. Pace
}

R.L. Baskett

This papcr was prepared for submittal to the

Space Technology \& Applications International Forum (STAIF-99)

Albuquerque, $N M$

January 31-February 4, 1999

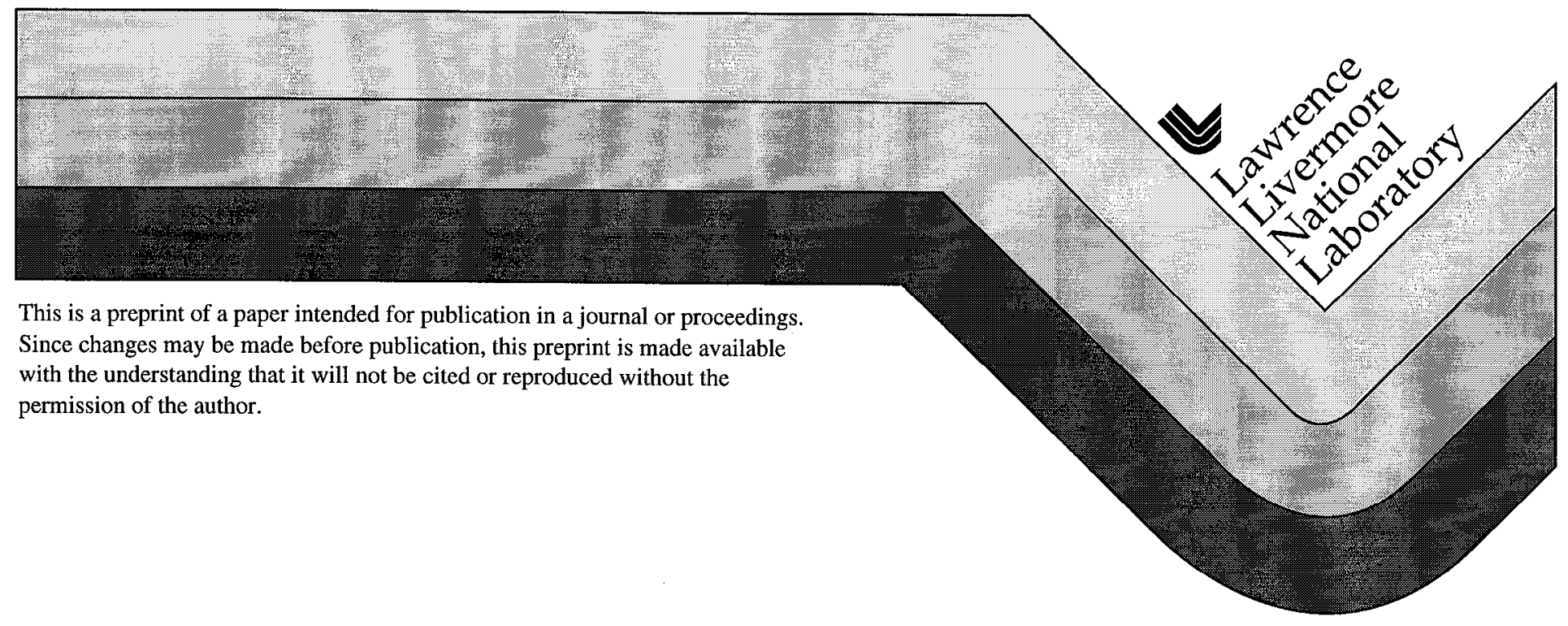




\section{DISCLAIMER}

This document was prepared as an account of work sponsored by an agency of the United States Government. Neither the United States Government nor the University of California nor any of their employees, makes any warranty, express or implied, or assumes any legal liability or responsibility for the accuracy, completeness, or usefulness of any information, apparatus, product, or process disclosed, or represents that its use would not infringe privately owned rights. Reference herein to any specific commercial product, process, or service by trade name, trademark, manufacturer, or otherwise, does not necessarily constitute or imply its endorsement, recommendation, or favoring by the United States Government or the University of California. The views and opinions of authors expressed herein do not necessarily state or reflect those of the United States Government or the University of California, and shall not be used for advertising or product endorsement purposes. 


\title{
ARAC's Operational Support of the Cassini Launch
}

\author{
John C. Pace and Ronald L. Baskett \\ Atmospheric Sciences Division, Lawrence Livermore National Laboratory, Livermore, CA 94551 \\ (925) 424-4858; jpace@Ilnl.gov
}

\begin{abstract}
The Atmospheric Release Advisory Capability (ARAC) program at the Lawrence Livermore National Laboratory (LLNL) was the U.S. Department of Energy atmospheric modeling resource used for the contingency of potential radiological releases during the launch of the Cassini mission. The ARAC Center at LLNL forecasted detailed weather conditions and delivered consequence assessments for potential accident scenarios to NASA before and during launch operations. A key aspect of ARAC's support was to acquire a variety of meteorological data for use in both forecast and real-time model calculations. ARAC acquired electronically two types of real-time observed meteorological data: 1) the full set of on-site towers and profilers via the Cape Canaveral Air Station (CCAS) Meteorological Interactive Data Display System (MIDDS), and 2) routine regional airport observations (delivered to the ARAC Center from the Air Force Weather Agency). We also used two forecasted data sources: 1) the U.S. Air Force 45th Weather Squadron at CCAS forecasted soundings for launch time, and 2) the Navy Operational Regional Atmospheric Prediction System (NORAPS) prognostic model which ARAC ran over the Cape. The NORAPS runs produced detailed 24-hr forecasts of 3-D wind fields. ARAC used default radiological accident source terms involving the potential destruction of Cassini's Radioisotope Thermoelectric Generators (R'TGs) during 3 phases: 1) before the launch, 2) during the first $5 \mathrm{sec}$ after ignition, and 3) from 5 to $143 \mathrm{sec}$ after ignition. ARAC successfully developed and delivered dose and deposition plots at 24 hours, 3 hours, and 30 minutes before each of the launch windows.
\end{abstract}

\section{INTRODUCTION}

The Cassini mission, conducted by the National Aeronautics and Space Administration (NASA) to study Saturn, has radioactive material on board the spacecraft to supply heat and electrical power. Although the risk of a release of radioactive material during the launch was very small, federal plans call for the Department of Energy (DOE) to provide emergency response support during the launch of any NASA mission involving radioactive materials.

The radioactive material used for Cassini is Plutonium-238 (Pu-238). Heat is supplied by 129 Radioisotope Heater Units (RHUs), each containing $2.56 \mathrm{~g}$ of $\mathrm{Pu}-238$, and electrical power is supplied by three Radioisotope Thermoelectric Generators (RTGs), containing a total of $32,700 \mathrm{~g}$ of Pu-238. The RHUs and RTGs are extremely well built, designed to withstand almost any catastrophic event, so even in the event of an accident under most conditions no nuclear material would have been released. In the rare cases where a release did occur, the total amount of released $\mathrm{Pu}-238$ was predicted to be between $.56 \mathrm{~g}$ and $360.14 \mathrm{~g}$, depending on the accident scenario.

DOE assigned the task of emergency response dispersion modeling during the Cassini launch to the Atmospheric Release Advisory Capability (ARAC) at the Lawrence Livermore National Laboratory (LLNL). The role of ARAC was to provide pre-launch guidance about where hazardous material would have gone if released, and in the event of an accident to provide refined calculations to help determine the magnitude of the release. This paper describes how ARAC carried out this mission.

\section{ARAC SYSTEM}

The ARAC mission is to provide timely and credible advisories for radiological (and other) hazardous releases to the atmosphere. Briefly, the ARAC system simulates the release of some material in the atmosphere and predicts its movement downwind. The system calculates the consequences to health of the release, based on known characteristics of the material.

ARAC has been designed to respond in near-real-time to releases anywhere worldwide. The flexible ARAC system has been used for many types of actual or exercise events (nuclear power plants, weapons, volcanoes, missile launches, oil fires, and many others). For non-routine applications such as support to NASA launches, ARAC's support is improved if equipment is deployed and plans are made before any potential release. 
The ARAC system (Sullivan et al., 1993) uses topographical and meteorological data to generate a time-varying series of three-dimensional mass adjusted wind fields, which are used to drive the ADPIC Lagrangian particle dispersion model. ADPIC is a three-dimensional model which accounts for the effects of spatial and temporal variation of mean wind and turbulence, gravitational settling, dry and wet deposition, and initial plume buoyancy and momentum.

ARAC personnel use horizontal and vertical cross-sections through the plume along with other displays to study and evaluate the structure of the plume, in order to decide whether the models are working optimally. Examples from a simulated release made in real time before a launch prior to Cassini (the Mars Pathfinder launch from December 1996) show complicated patterns due to strong wind shear within the model domain (Figs 1 and 2). A thorough understanding of the three-dimensional wind pattern is critical to accurate dispersion modeling.

The ARAC models have been extensively evaluated during many field tracer studies, and the results show the system is highly accurate when the source term is well known and the meteorological conditions are well represented (Foster and Dickerson, 1990). ARAC's system allows use of multiple sources of meteorological data, and ARAC used different types of meteorological data for Cassini, as discussed below.

\section{HOW ARAC PLOTS WERE USED}

ARAC generated pre-launch plots before the Cassini launch, and was prepared to perform additional calculations if there had been an actual release. The primary purpose of the pre-launch plots was to provide guidance to NASA response officials about where a release would go if it occurred. They used this information to pre-deploy field measurement teams, who would have sampled the air and ground to define the radioactive cloud (where did it go, when did it get there, and how much was in it) had there been an a release.

In addition, plots showing predicted conditions at various levels above the ground at 30 min intervals were very helpful for planning flights which would have sampled any airborne plume.

If there had been an accident, ARAC would immediately have made new calculations based on the actual time of the accident, using or modifying the pre-defined release scenario as appropriate. As field measurement reports became available, they would be input to the ARAC models, which would be re-run with adjusted source information so the predictions matched the measurements. In this way, ARAC would help determine the magnitude of the release.

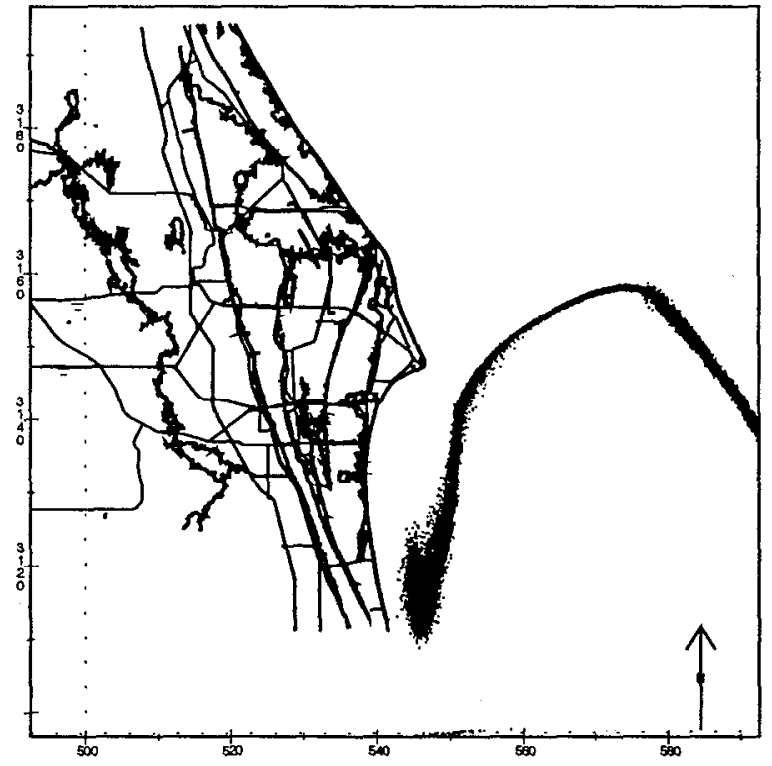

FIGURE 1. Overhead view of ARAC particle positions for Mars Pathfinder calculation, $2 \mathrm{hr}$ after simulated release at 0658 UTC on 4 Dec 96 . Horizontal scales are Universal Transiverse Mercator (UTM) distances, equivalent to $\mathrm{km}$.
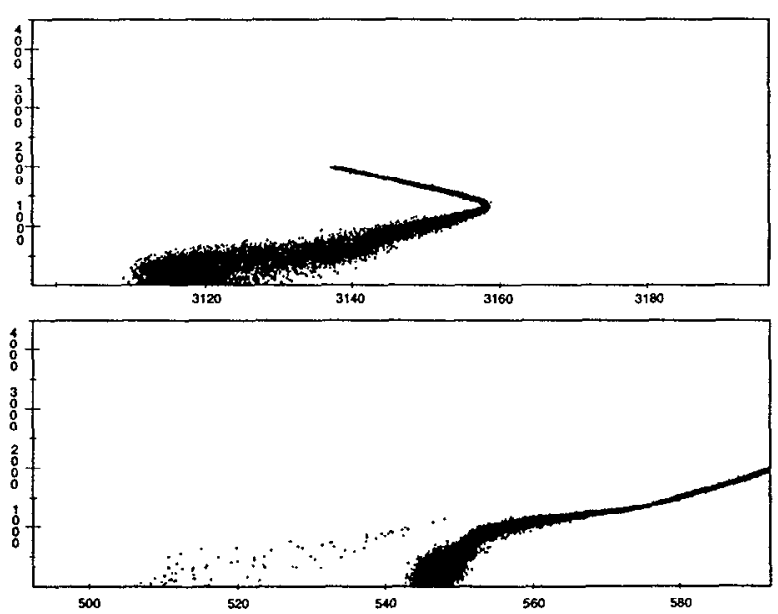

FIGURE 2. Side views of $A R A C$ particles for Mars Pathfinder calculation, $2 \mathrm{hr}$ after simulated release at 0658 UTC on 4 Dec 96. (Top) View from east to west. (Bottom) View from south to north. Vertical scale is $\mathrm{m} A G L$. 


\section{MODELING CONSIDERATIONS}

ARAC did not model the explosive cloud rise that would occur during an accident involving a rocket. Instead, ARAC used the results of previous NASA and DOE studies which predicted the configuration of the stabilized cloud following the dissipation of the immediate heat and buoyancy effects, and the distribution of the radioactive material in the cloud. Because the source terms were well-specified, the primary challenge for ARAC was to represent the complex wind patterns in the Cape area.

ARAC used several meteorological data sources for its Cassini calculations. One source was forecasted vertical wind profiles (which were remarkably accurate) generated by a forecaster of the U.S. Air Force's 45th Weather Squadron (45 WS) at Cape Canaveral Air Station (CCAS). A second source was weather observations from the many sensors arrayed around the Cape (over 40 instrumented, multi-level meteorological towers, rawinsonde soundings, a $50 \mathrm{MHz}$ profiler, and five $915 \mathrm{MHz}$ profilers). These observations are collected automatically by the CCAS Meteorological Interactive Data Display System (MIDDS).

ARAC developed a new software package allowing display and editing of the tower, sounding, and profiler data retrieved from MIDDS. Using this package ARAC personnel performed quality control of the MIDDS data before their use in the ARAC models.

An important new ARAC capability for Cassini was provided by implementing the Navy Operational Regional Atmospheric Prediction System (NORAPS). NORAPS is a weather forecast model developed by the Navy Research Laboratory, which has been used operationally for several years at the Fleet Numerical Meteorology and Oceanography Center and which was supplied to ARAC through an interagency support agreement. To use NORAPS to support Cassini, ARAC accelerated the work needed to bring NORAPS into an operational state at LLNL. NORAPS provided high-resolution, time-varying meteorological data for the ARAC models described above.

ARAC therefore had access to four types of meteorological data: forecasted soundings; MIDDS reports of local sensors; NORAPS output; and surface and upper air observations from the region, which ARAC collects routinely from the Air Force Weather Agency. ARAC has automated procedures to retrieve, store, and use each of these types, and can run its models with these sources individually or in any combination.

Except for changes to accommodate the new meteorological data sources, ARAC used its existing, well-tested, validated models to support Cassini.

\section{ARAC PREPARATIONS FOR CASSINI}

ARAC's preparations for Cassini were very extensive. Four ARAC scientists deployed to Florida, along with three ARAC computer systems. All model calculations were done at LLNL, but the on-site personnel assisted in interpretation of the model results and acted as interfaces to the staff at LLNL, describing current conditions and channeling requests for support.

The deployed ARAC people and computers were located in two separate facilities. Two meteorologists worked in the Radiological Control Center (RADCC), which was located at KSC. Two Site Workstation Systems (SWSs) were also set up at the RADCC. The SWS collects meteorological data, electronically transfers accident release information from the site to the ARAC Center in Livermore, California, and receives model products delivered from the LLNL ARAC Center. The RADCC supported activities at the Range Operations Control Center, where the senior launch officials directed operations. A third meteorologist, with a portable SWS, was deployed to the Advance Launch Support Group (ALSG) facility, located in an armory in Cocoa Beach. The ALSG would have been the center of operations coordinating the response to an off-site release of nuclear material. The fourth ARAC person was a technician who was on-site to set up the equipment and resolve any problems. Additional ARAC staff were on duty at the ARAC Center at LLNL, running NORAPS, evaluating meteorological data obtained from MIDDS, generating products, and coordinating with the deployed personnel. NASA procedures required ARAC to be available and operational in order for the launch to proceed.

Based on the NASA and DOE studies, there were three categories of potential release scenarios, and ARAC modeled one representative scenario for each category. These three categories pertained to releases before the launch, during the first $5 \mathrm{sec}$ after ignition, and from 5 to $143 \mathrm{sec}$ after ignition. (Beyond $143 \mathrm{sec}$ after ignition, the spacecraft would have fallen into the ocean, and no release of nuclear material was possible resulting from an impact on water.) For each scenario, ARAC created tailored inputs for its dispersion model, taking into account the size distribution of the released particles, which is extremely important in predicting the associated health effects, and the predicted vertical and horizontal distributions of released material. 
Communications is a critical component of any ARAC response. The MIDDS data retrieval (mentioned above) and all communications between LLNL and the deployed personncl and equipment werc donc over dedicated communications circuits provided by DOE's Remote Sensing Laboratory (RSL). We also used telephone circuits and modems as a backup system. The three ARAC computer systems deployed to Florida were configured to operate with all our available communications options, and to provide the capability to view, use, and edit the MIDDS data. ARAC worked with communications personnel from NASA/KSC as well as RSL to design, configure and test the system used for launch support.

ARAC coordinated with 45 WS personnel to get access to MIDDS data and to obtain the forecasted vertical wind profiles. In addition, the Air Force detailed a weather forecaster to work alongside the ARAC personnel in the RADCC, assisting in interpretation of local weather conditions. ARAC's support from the 45 WS was excellent.

ARAC also coordinated with the 45th Space Wing Safety Office and its supporting contractor (ACTA, Inc.), which operate a dispersion model (Rocket Exhaust Effluent Diffusion Model, or REEDM), used before every launch at CCAS/KSC to predict the behavior of the clouds of toxic chemicals which result from all launches. Although ARAC did not model the toxic cloud from Cassini, the similarity between the ARAC and ACTA/Safety missions led to cooperation and improved capabilities. ARAC and ACTA cooperated on a post-event evaluation of the toxic cloud resulting from the explosion of a Delta-II rocket at CCAS on 17 January 1997 (Pace et al, 1998).

\section{ARAC PRODUCTS FOR CASSINI}

NASA requested delivery of relatively few plots from ARAC for pre-launch support. However, ARAC generated considerably more plots, to be prepared in case they were needed.

ARAC generated 50-Year Committed Effected Dose Equivalent (CEDE), Total Ground Deposition, and Instantaneous Air Concentration plots for various levels above the ground, all valid at $30 \mathrm{~min}$ intervals out to $6 \mathrm{hr}$ after a simulated release at the beginning of each day's launch window. (Note that the launch windows were 140 min long; the actual time of a launch and therefore of any release could have been different than the time used in ARAC's calculations.) The reason for generating plots valid at these intervals was to illustrate the evolution of the release, allowing better response by emergency responders.

However, the only plots ARAC sent to NASA were a single CEDE plot and a single deposition plot for each of the three release scenarios, each plot valid $6 \mathrm{hr}$ after a simulated release at the beginning of each day's launch window. ARAC generated these six plots at three times $(24 \mathrm{hr}, 3 \mathrm{hr}$, and $30 \mathrm{~min}$ ) before each launch window, and sent the CEDE and deposition plots for each scenario to NASA using a Geographical Information System operated by RSL. This provided NASA officials with only the pre-launch plots they needed to prepare in case an accident occurred, without the need to receive many other plots they probably would not need.

The plots not sent to NASA were instead sent to the deployed ARAC personnel to have in-hand in case they were needed. If an accident had occurred, there would have been no time to create those plots; they would have been needed immediately. This dual approach provided access to the appropriate ARAC products for pre-launch support and any potential accident response activities.

In the event of an accident, ARAC would have immediately generated a new set of plots based on the actual time of the release, using the latest available meteorological data. Then, as field measurement data were reported, ARAC would have begun generating refined plots in which the field measurements were incorporated. The purpose of these plots would have been to improve the ARAC representation of the plume, and to provide an updated understanding of the actual source term.

\section{SUMMARY}

This overview describes the preparations and modifications to its system ARAC carried out to support the Cassini mission. Of course one hopes ARAC is never called upon to respond to actual accidents, but the extensive preparations made it possible for ARAC to respond quickly and effectively if the need arose.

\section{ACKNOWLEDGMENT}

This research was performed under the auspices of the US Department of Energy Lawrence Livermore National Laboratory Contract No. W-7405-ENG-48. 


\section{REFERENCES}

-.. Foster, K. T. and Dickerson, M. H., 1990, “An Updated Summary of MATHEW/ADPIC Model Evaluation Studies," UCRL-JC-104134, Lawrence Livermore National Laboratory, Livermore, CA.

Pace, J.C., Albritton, J. R., Baskett, R. L., Zhang, X. J., Masonjones, M. C., Moussa, N. A., Overbeck, K., Parks, C. R., and Evans, R. J., "Modeling the 17 January 1997 Delta-II Explosion by ARAC, ADORA, and REEDM," in American Meteorological Society / Air \& Waste Management Association Tenth Joint Conference on the Applications of Air Pollution Meteorology Proceedings, 1998, pp. 294-301.

Sullivan, T. J., Ellis, J. S., Foster, C. S., Foster, K. T., Baskett, R. L., Nasstrom, J. S., and Schalk, W. W., Bull. Amer. Meteor. Soc. 74, 2343-2361 (1993). 